\title{
Laboreal
}

Volume $4 \mathrm{~N}^{\circ} 2$ | 2008

A inovação

\section{A inovação : entre o trabalho dos projetistas e o trabalho dos operadores}

La innovación : entre el trabajo de los proyectistas y el trabajo de los operadores L'innovation: entre le travail des concepteurs et le travail des operateurs Innovation : between the work of designers and the work of operators

\section{Pascal Béguin and Francisco Duarte}

\section{(2) OpenEdition}

1 Journals

\section{Electronic version}

URL: http://journals.openedition.org/laboreal/10988

DOI: 10.4000/laboreal.10988

ISSN: 1646-5237

\section{Publisher}

Universidade do Porto

\section{Electronic reference}

Pascal Béguin and Francisco Duarte, «A inovação : entre o trabalho dos projetistas e o trabalho dos operadores », Laboreal [Online], Volume $4 \mathrm{~N}^{0} 2$ | 2008, Online since 20 September 2019, connection on 24 September 2020. URL : http://journals.openedition.org/laboreal/10988 ; DOI : https://doi.org/ 10.4000/laboreal.10988

This text was automatically generated on 24 September 2020.

Laboreal está licenciado com uma Licença Creative Commons - Atribuição-NãoComercial 4.0 Internacional. 


\title{
A inovação : entre o trabalho dos projetistas e o trabalho dos operadores
}

\author{
La innovación : entre el trabajo de los proyectistas y el trabajo de los operadores \\ L'innovation: entre le travail des concepteurs et le travail des operateurs \\ Innovation : between the work of designers and the work of operators
}

Pascal Béguin and Francisco Duarte

1 O 9o simpósio internacional ODAM, realizado em Março de 2008 no Guarujá, Brasil, teve como tema "Compreender e Transformar o Trabalho pela Inovação". Este número especial da revista Laboreal teve origem neste evento. Os textos de algumas comunicações então apresentadas, foram retrabalhados e reformulados por seus autores, com o objectivo ir mais longe na reflexão e avançar na compreensão da inovação, processo esse, potencialmente criativo de transformação da realidade.

2 Não é surpreendente ver um simpósio centrado sobre os Human Factors in Organizational Design and Management (ODAM) tratar da inovação. Esta temática tem sido, em todo o mundo, objeto de numerosos discursos científicos, políticos e até ideológicos. Trata-se de um tema muito amplo. A fim de apresentar os textos desse dossier, apresentaremos inicialmente como este termo é aqui compreendido.

\section{Concepção e Inovação}

3 Na linguagem corrente, a noção de inovação é freqüentemente utilizada como sinônimo de novidade. Um produto "inovador" é na realidade um produto "novo".

4 De fato, a inovação diz respeito à "concepção" (criação de algo que ainda não existe) em vez de "descoberta" (identificar o que já existe, mas, que não ou mal se compreende). Entretanto, a noção de concepção é, ainda, mais ampla do que a de inovação. A inovação é somente um plano de análise da concepção. 
5 Em uma obra particularmente bem documentada [1], Staudenmaïer (1985) mostra que três processos distintos são necessários para se apreender as dinâmicas de concepção: a invenção, o desenvolvimento e a inovação. Vejamos o que cobrem estes termos :

- No plano historiográfico, a noção de "invenção" é a mais antiga, sendo contemporânea da renascença (século XV). A invenção é, freqüentemente, apreendida como um ato misterioso, às vezes heróico e que sempre nos remete às características do inventor (por exemplo, Leonard da Vinci). Falar da invenção é situar a emergência da novidade no universo mental de um criador. Em ergonomia, pode-se encontrar um exemplo recente de análise da invenção em Theureau e Donin (2008).

- o termo "desenvolvimento" é muito mais recente, sendo contemporâneo da $2^{\text {a }}$ guerra mundial. Ele emerge no contexto da reconstrução do pós guerra, em particular do plano Marshall, para responder a amplitude de projetos que esta reconstrução demandava. 0 "desenvolvimento" se caracteriza por uma atividade coletiva e finalizada de elaboração e de validação de modelos visando um determinado objetivo. Trata-se, de fato, da gestão de projetos, noção com uma cartografia maior e fortemente abordada em ergonomia. Se a invenção é individual e abstrata, o desenvolvimento é um trabalho de grupo, que conduz à necessidade de uma reflexão organizacional (Daniellou \& Béguin, 2007).

- A noção de inovação será introduzida pelos economistas, notadamente, por Schumpeter no início do século 20. Este autor se interessa aos fenômenos ligados à aparição ou à promoção de uma novidade sobre o mercado. Mas os autores da história das técnicas e todos aqueles que tentaram desenvolver uma "ciência das técnicas" utilizam este termos para caracterizar a última etapa da gênese da técnica : a "eclosão" da novidade técnica (artefato, produto, processo) em situações concretas. Para Staudenmaïer a inovação se caracteriza pelo fato de que o projeto (o desenho), assim como o contexto (cognitivo, organizacional, material,...) escapam ao controle do projetista em prol dos receptores, gerando um movimento nas características do objeto concebido (Staudemmaïer, op. cit). A inovação designa, portanto, um processo potencialmente criativo, de reinterpretação e re-concepção de uma novidade sem o qual não ocorrerá a transformação concreta dos meios de vida ou de trabalho.

6 Existem, aqui, três planos de análise da concepção. Enquanto a invenção se situa no universo mental do projetista, o gerenciamento do projeto (desenvolvimento) nos reenvia ao ato matricial da concepção em suas diferentes dimensões organizacionais (temporalidade, diferenciação de tarefas e de atores, gestão da interdependência,...). Quanto à inovação, ela é centrada, sobretudo, nas relações de recomposição entre as atividades que ocorrem em diferentes meios de vida e uma novidade técnica (que seja um novo artefato, um novo processo ou um novo produto).

7 Entretanto, pode-se notar bem claramente que, mesmo com estas distinções, a noção de inovação é, ainda, uma categoria muito ampla, uma vez que ela diz respeito às ligações entre técnica e sociedade. Ela é, portanto, apreendida de maneira muito diferente de acordo com as disciplinas científicas.

8 Na literatura, a abordagem da economia da inovação é, atualmente, dominante : a inovação é essencialmente apreendida como um fator de competitividade entre as empresas. Nos anos 80 , esta análise econômica foi traduzida pelas "novas estratégias" de concepção como a engenharia simultânea ou concorrente. A finalidade dessas estratégias era, de fato, reduzir os tempos de concepção e de fabricação de produtos : a rapidez de colocação de produtos novos no mercado era e, ainda é, um importante fator de concorrência (Perrin, 1997 ; Le Masson, Weil \& Hatchuel, 2006). O interesse dessa abordagem econômica da inovação se amplifica na medida em que chegam ao mercado 
os países ditos "emergentes", cuja produtividade é superior à das economias ocidentais do hemisfério norte, principalmente devido ao baixo custo do trabalho. Neste contexto, "inovar" é produzir, em alta velocidade, produtos novos geradores de valor, uma vez que vão ao encontro de necessidades (consumidores irão comprá-los) que, frequentemente, são criadas pelo mercado.

9 Entretanto, essa abordagem econômica não esgota o campo e, inclusive, não é ela que será tratada aqui. Enquanto categoria crítica que trata das ligações entre técnica e sociedade, a temática da inovação questiona, fortemente, as formas institucionalizadas de condução da mudança, cujas "externalidades negativas" [2] são numerosas. 0 risco (nuclear e vários outros) que caracteriza hoje o conjunto de nossa sociedade (Beck, 1986), os grandes desafios mundiais (ecológico ou energético) constituem as tais "externalidades negativas" que vão além das questões econômicas e que dizem respeito ao futuro da humanidade.

Do nosso ponto de vista, a temática da inovação coloca em cena a necessidade de uma requalificação das abordagens de concepção[3]. Trata-se de "encontrar os caminhos da ação" (Futuris, 2004). E para nós, ergonomistas, trata-se de encontrar os caminhos da ação mais favoráveis ao trabalho humano.

\section{Inovação e trabalho}

11 Este dossier está focado em apenas uma das externalidades negativas das estratégias de condução da mudança: aquela relacionada à incapacidade atual de considerar o trabalho humano nas transformações em curso. Se o ponto de vista é preciso ; o que está em jogo é potencialmente muito vasto : caminha-se da saúde dos trabalhadores (Daniellou, 2005) até a interrogação antropológica sobre o desenvolvimento das indústrias e dos países (Wisner, 1985).

\subsection{Trabalho e novidade}

Enfatizamos, no início desta introdução, que a temática da inovação diz respeito ao conjunto de ligações entre técnica e sociedade. No entanto, poucos são os trabalhos que se interessam pelas vivências e ações dos produtores, dos trabalhadores assalariados e terceirizados face à mecanização, à automação industrial ou à racionalização dos serviços na grande indústria ou nas PMEs? As situações de trabalho estão fora da sociedade ? Evidentemente que não.

13 Pareceu-nos ser de utilidade examinar a natureza e a forma das relações de composição existentes entre a atividade de trabalho (individual e coletiva) e a novidade técnica. Trata-se de examinar a contribuição criativa, de reinterpretação e de reconcepção que experimentam as atividades de trabalho e sem as quais não haveria mudança concreta no meio industrial. Trata-se, também, de testemunhar as dificuldades que encontram os trabalhadores face às inovações atuais. Três artigos tratam dessa questão.

Catarina Silva e Marianne Lacomblez oferecem um quadro analítico pouco usual para compreender as organizações pósfordistas, em especial quanto aos mecanismos de racionalização da produção, controle da qualidade e do tempo, sem cair na dicotomia tradicional entre controle rígido e autonomia. São apresentadas as inovações implementadas numa empresa e a vivência dos operadores diante de tais inovações. 0 
artigo contribui, ainda, para discutir as condições organizacionais dos processos de aprendizagem e desenvolvimento de competências, que podem ser utilmente confrontadas aos modelos de flexibilidade e de gestão do conhecimento.

Sandrine Caroly, Daniel Depincé e Pascal Lecaille se interessam pelas inovações contínuas, conduzidas pelos chefes de equipes na gestão da produção. A inovação, neste caso, nos remete às modificações incrementais realizadas nas empresas para manter a competitividade. Entretanto essas inovações, em situação, são incapazes de levar em consideração as condições de trabalho dos operadores. É, mesmo, o crescimento da LER/DORT (TMS) na empresa que está na origem do estudo. Trata-se então de instituir, na empresa e de se inscrever em sua organização, as "interfaces" estabilizadas que permitem tomar consciência e objetivar aquilo que está em jogo nos processos de mudança.

O terceiro texto, de Johann Petit, é centrado sobre as atividades dos operadores confrontados à uma mudança organizacional numa empresa de seguro ou mútuo de saúde. Trata-se, para dizer como o autor, de examinar uma fase de transição organizacional, sinônimo de mudanças cognitivas e sociais. $\mathrm{O}$ autor se situa numa perspectiva muito próxima daquela de Staudenmaïer : durante a inovação, o contexto pertinente para a condução da mudança está situado e deve ser examinado na sua singularidade cognitiva, organizacional e material. No entanto, para Johann Petit, esta contextualização não tem nada de espontâneo. Ela demanda uma "estrutura operativa" que deve permitir de conduzir experimentações em situações fonte de aprendizagens. $O$ autor discute as condições de operacionalização dessa estrutura e, também, a forma que poderia apresentar este "espaço de aprendizagem" para os próprios empregados da empresa.

\subsection{O lugar do trabalho e dos trabalhadores na condução do projeto}

17 A segunda temática apresenta a criatividade dos usuários e as dificuldades potencias que a acompanham. Trata-se gora de questionar as estratégias de gestão dos projetos (o desenvolvimento no sentido de Standenmaïer, apresentado acima) em suas formas instituídas.

18 Três artigos desse dossier apresentam a relação entre gestão de projeto e trabalho, focalizando as interações entre o trabalho dos projetistas institucionais e a concepção de seu próprio trabalho pelos operadores.

Ole Broberg apresenta o programa de pesquisa sobre o projeto de espaços de trabalho desenvolvido na Dinamarca, caracterizado pelo diálogo entre usuários e engenheiros em workshops participativos. Esse diálogo, apoiado por diversos objetos intermediários (tais como cadernos de anotações, tabuleiro do jogo de layout e modelos 3D, entre outros) permitiram, no caso apresentado pelo autor, de mudar o foco de um projeto de engenharia : de uma orientação centrada na dimensão técnica passou-se a considerar os processos de trabalho e as características do ambiente. $O$ autor destaca, ainda, o papel do ergonomista (ou projetista do espaço de trabalho) na condução do processo de transformação.

20 Francisco Duarte, Carolina Conceição, Cláudia Cordeiro e Francisco Lima, também, se interessam pela concepção de espaços de trabalho, em especial, pelo projeto de um novo centro de controle de distribuição de gás e óleo. Suas análises estão centradas sobre as relações entre a produção de especificações pelos engenheiros e arquitetos e 
sua efetivação em situação. Os autores destacam que as soluções propostas pelos projetistas são de natureza a gerar incertezas ou a levantar novas questões que necessitam ser identificar para orientar o desenvolvimento do projeto. Schön (1987) colocou em evidência, esta dimensão na célebre metáfora do "diálogo com a situação". o projetista, orientado por um objetivo, projeta soluções a partir de idéias e saberes, mas a situação lhe "responde" : ela apresenta resistências que o conduzem a reformular o problema e a fazer evoluir as soluções. Trata-se, portanto, de um processo cíclico. Duarte et al. fazem desse "diálogo com a situação" o princípio organizador do processo de projeto. Trata-se de inscrever a efetividade da ação nesse processo cíclico. Esta análise coloca em evidência uma vasta gama de exemplos desse processo e do diálogo envolvendo usuários finais (operadores da sala de controle) e, também, os operários do canteiro de obras.

21 Pascal Béguin, centra igualmente sua análise sobre o processo dialógico da concepção, mas ele o examina na sua temporalidade. Neste artigo, o autor discute as razões pelas quais a concepção continua durante o uso. Inicialmente são apresentadas as diferenças teóricas e epistemológicas entre três orientações da ergonomia da atividade na concepção, identificadas como : cristalização, plasticidade e desenvolvimento. Apesar das diferenças, o autor apresenta um modelo dialógico da concepção como articulador dessas diferentes orientações. Sobre esta base se argumenta que a concepção é um processo de desenvolvimento conjunto do artefato e da forma de ação. Para o autor, é justamente esse encontro entre artefato e ação, definido como "instrumento", que é necessário conceber.

\section{Perspectivas}

Provavelmente não seja possível uma síntese das contribuições desenvolvidas nesse número especial da revista Laboreal. Mas pode-se, no entanto, indicar algumas orientações que emergem como tendência. Do nosso ponto de vista, os textos desse dossier colocam três questões principais.

A primeira é sobre o policentrismo. O processo de inovação coloca em cena um conjunto diverso de pontos de vistas, de saberes, de necessidades e de procedimentos,... Esta temática não está ausente da gestão dos projetos que é, na realidade, transdisciplinar. A fim de se evitar a cacofonia, é necessário articular os procedimentos, os conhecimentos e os objetivos perseguidos pelos diferentes protagonistas de um projeto. A partir da leitura dos textos, aqui apresentados, podemos nos demandar se a questão é aquela de integrar os saberes dos operadores ou então de conceber situações adaptadas a uma grande diversidade de contextos e meios. Em outros termos, trata-se de organizar uma polifonia para inscrever a diversidade de posições num mesmo foco ou trata-se de configurar saberes e procedimentos e caminhar na direção de um mundo policêntrico? Essas duas questões não são contraditórias, mas, entre as duas, as diferenças são profundas.

A segunda trata da variável histórica. O conjunto de textos apresentados aqui trata de melhor compreender e considerar a variável humana das inovações em todas as suas dimensões (sociológica, psicológica e antropológica). Ora é essencialmente a variável histórica que está em jogo. Variável histórica devido ao fato que a inovação é uma propriedade relativa à um dado meio, já rico de sua própria história e de suas "normas antecedentes" para retomar o termos de Schwartz (1992). Deste ponto de vista quais 
são as relações entre uma ciência da concepção e uma ciência da evolução, das gêneses e dos processos de mudança?

A terceira questão é sobre as relações entre conhecimento e ação. Consideramos, freqüentemente, que para tomar decisões é necessário, inicialmente, construir um conhecimento comprovado e que sobre esta base se define as finalidades e os meios correspondentes. Os trabalhos apresentados aqui, nos deixam entrever $\mathrm{m}$ esquema diferente : a efetivação da ação em situação, o uso de uma novidade técnica produz um conhecimento novo que não é completamente possível de se identificar a priori. Esta é a razão pela qual se torna necessário construir "interfaces" entre projetistas e operadores ou realizar experimentações. Como organizar, como definir e como colocar em cena dispositivos que articulem a construção de saberes e a elaboração da ação ?

\section{BIBLIOGRAPHY}

Beck, U. (1986). Risikogesellschaft. Francfort : Suhrkamp Verlag.

Béguin, P. \& Cerf, M. (no prelo). Dynamique des savoirs, dynamique des changements. Quelles pratiques de recherche pour quels développements? Toulouse : Edições Octarès.

Daniellou, F. \& Béguin, P. (2007). Metodologia da ação ergonômica : abordagens do trabalho real. In P. Falzon (ed.), Ergonomia (pp. 281-301). São Paulo : Edgard Blücher.

Daniellou, F. (2005). Santé au Travail. Sciences Humaines, n horssérie "La santé", Fevereiro de 2005.

Le Masson P., Weil B., \& Hatchuel A. (2006). Les processus d'innovation. Conception innovante et croissance des entreprises. Paris : Hermès - Lavoisier.

Perrin, J. (1997). Les enjeux économiques de l'ingénierie concourante. In P. Bossard, C. Chanchevrier \& P. Leclair (eds), Ingénierie Concourante, de la technique au social (pp. 29-38).

Paris : Economica.

Schwartz, Y. (1992). Travail et Philosophie. Convocations mutuelles. Toulouse : Edições Octarès.

Staudenmaier, J. M. (1985). Technology's Storytellers. Cambridge : MIT Press.

Theureau, J. \& Donin, N. (2008). Du travail et de la conception à la création artistique et retour. Anais do 43 Congresso da SELF, Ergonomie et Conception (pp. 280-284).

Wisner, A. (1985). Quand voyagent les usines. Essai d'anthropologie. Paris : Syros.

Wisner A. (avec B. Pavard, T. H. Benchekroun \& Ph. Geslin) (1999). Anthropotechnologie. Vers un monde industriel polycentrique Toulouse : Edições Octarès.

\section{NOTES}

1. Trata-se de uma revista em livro que tenta sintetizar 272 artigos surgidos entre 1959 e 1980 na revista da Society for History Of Technology: "Technology and Culture" 
2. A noção de externalidade negativa designa uma situação na qual o ato de um agente influi negativamente sobre a situação de um outro agente não implicado na ação. Por este termo, designa-se, aqui, os efeitos negativos que são gerados pelas formas atuais de gestão de projetos. 3. $\mathrm{E}$ de pesquisa: ver sobre este ponto Béguin \& Cerf (no prelo).

\section{AUTHORS}

\section{PASCAL BÉGUIN}

Institut National de la Recherche Agronomique 147 rue de l'université, 75338 Paris Cedex 07, France

pbeguin@grignon.inra.fr

\section{FRANCISCO DUARTE}

Programa de Engenharia de Produção COPPE/ Universidade Federal do Rio de Janeiro Caixa postal 68507, CEP 21945-972, Rio de Janeiro, Brasil

duarte@pep.ufrj.br 